\title{
The role of posturography on the initial stage of sports training
}

\author{
Boris Podlivaev $^{1 *}$, Vladimir Kurashvili ${ }^{1}$, Elena Sinyuchkova ${ }^{1}$, Alexandr Kuznetsov ${ }^{2}$ \\ ${ }^{1}$ Federal Center of Sports Reserve Training, 105064, Moscow, Russia \\ ${ }^{2}$ Chaykovskiy State Institute of Physical Culture, 617764, Chaykovskiy, Russia
}

\begin{abstract}
One of the main directions in the wrestlers training on the initial stage of sports training is the formation of the wrestler's motion coordination abilities. Equilibrium function and anthropometric data including wrestler's gender have essential differences in connection both with the child's biological specialities and choosen athletic discipline special aspects. This research is focused on comparsion of variations in kinetic postural control affected by the lassitude among young athletes and non-athletes. 16 girl childs - freestyle wrestlers participates in this research. They are on initial stage of sports training. The control group consisted of 14 girl childs irrelevant to sports. There was made a hypothesis that the wrestlers lassitude can be measured subjectively (with the Borg scale) and objectively (with the stabilometrics), and that the wrestlers will better control their body position than the girls irrelevant to sports. Tecnobody Pro-Kin stabilometric platform was used to measure postural balance. There was determined statistically significant positive relationship of the investigated parameters changes between groups. As a result of the research we can make a conclusion that the offered method can provide reliable data concerning wrestler's lassitude level. Analogues data are received with the rating of perceived exertion by Borg's scale. As the result we can conclude that the offered postural balance research method is valid for the wrestler's lassitude rating and can be used as a component of the complex athletes control system.
\end{abstract}

\section{Introduction}

Numerous researches figured that the formation of coordination capabilities in martial arts flows on the initial stage of sports training (athletes aged $10-14$ ). Young athletes aged 13-14 start using precise physical actions in sparrings [1].

Athlete's equilibrium function and anthropometric data have essential differences in connection with the athletic disciplines specific character. Each athletic discipline has unique anthropometric characters, different motor performance level and athlete's coordination abilities [2].

Coordination abilities form most actively from 9-10 to 11-12 years-old. Child's sensitive periods have essential individual variabilities, associated with the approaching of biological ripeness [3].

\footnotetext{
*Corresponding author: podlivaevb@mail.ru
} 
By comparison of gender differences was found that the female children in comparsion with the male children are less strong and enduring, but they have greater precision of movements, coordination and flexibility [5].

There are high demands on abilities to keep body's balance in sports. The low balance ability causes at the best case lowering of competitive results $[6,7,8]$.

It was shown that there are correlation relationships in control of the erect posture with the different human's anthropometric data, such as height $[9,10]$, height of foot arch [11], length of foot and width of calx [12], body weight [13], chest circumference, length of legs and body [14].

It was also shown that the key factor of increased female's vertical stability according to the male's one was the lower height [15].

There was made comparison of postural stability between athletes with different training orientations in the review [16]. Postural balance ability is the essential component of high results in many athletic disciplines. Postural stability was measured with stabilometrics over wrestlers, runners, soccer players, ice-hokey players, and also over non-athletes (altogether 121) in normal standing position with opened eyes, with closed eyes and in bent standing position. It was found that the players made the best of visual cue, wrestlers were best stable in normal standing position with closed eyes, runners have relatively low frontal stability.

Training loads that overrides athlete's physiological capabilities lead to lassitude, lowering of statokinetic stability and disbalancing of body equilibrium regulating mechanism, especially in precise athletic disciplines $[17,18]$.

This research is focused on comparsion of changes in dynamic postural control affected by the lassitude over young athletes and non-athletes. Our hypothesis is that the lassitude can be measured subjectively (with the Borg's scale) and objectively with the stabilometrics and that the female athletes will better control the body position than non-athletes females.

\section{Materials and methods}

16 female freestyle wrestlers on the initial stage of sports training took part in this research. Average age of participants was $12,43 \pm 2,25$ years. Average height $-155,25 \pm 6,90 \mathrm{~cm}$, average height $-36,37 \pm 8,24 \mathrm{~kg}$, average body-weight index $-18,5 \pm 1,63 \mathrm{~kg} / \mathrm{m}$. The athletes height was measured with the standard height meter with the sensitivity equal to 0,1 ; body weight and body-weight index was measured with the segmentary body analysis system Tanita BC-418 (Tanita Corporation, Tokyo, Japan). Longitudinal, lateral and circumference body measurements and thickness of skin folds were measured over all the participants. Body proportions were measured on the basis of longitudinal and lateral body dimensions to body length percentage ratio. Body weight components were measured by the formulae offered by $\mathrm{J}$. Mateigka. Somatotype was defined by the methods of B. Heath и J. Carter.

The control group consisted of 14 same age and weight non-athletes.

\section{Loading tests}

The loading test consisted of three 2-minutes periods of special exercises with the pauses between periods for 30 seconds. The exercises in all the periods were equal. Each period the athlete should do 4 exercises for 20 seconds with the 10 seconds "rest" pauses. The quantity of wraps was counted within each 20 seconds, within the period ( 2 minutes) and within all periods (6 minutes), and it's equal to the time of sports duel. Total time of test execution in one period is $4 * 20$ seconds $+3 * 10$ seconds $=1$ minute 50 seconds, i.e. almost equal to the period of sports duel. All 4 exercises replicates basic action elements (takedowns, pushes, protection, counterattacks).

Evaluation of perceptual loads 
Rating of perceived exertion was measured with the Borg's scale. This scale is concerned with the hearth rate and VO2max. It shows the exercises intensity and the load. The higher values means the higher load, higher VO2max and higher lassitude.

Evaluation of postural balance

Stabilometric platform TECNOBODY PRO-KIN was used For the postural balance measurement.

The athlete stands on stabiloplatform, takes vertical position, the legs position was according to European standing position (heels in, toes out at an angle of $30^{\circ}$ ). Voluntary movements of participants were denyed. The normal stand position with opened and closed eyes was also researched. Each test lasts 30 seconds and was registered as a stabilogram.

There was implemented the possibility of digital statokinesiograms and stabilograms analysis in the program complex. The following methods are included in the data analysis:

1) calculation of the average values on statokinesiogram;

2) calculation of the statokinesiogram area, containing $90 \%$ of discrete positions;

The finger-nose test

All the athletes passed the finger-nose test. The athlete stands upright with the foots moved together, closed eyes and the hands hold out before himself. After that the athlete should touch his nose with the index fingers of both hands.

Statistical processing

Shapiro-Wilk test was used to evaluate the nature of quantitative data pattern. Pairwise comparison of two groups by quantitative parameters was made by the means of Mann-Whitney U-test with the critical value $\mathrm{p}$ of 0,05 . To evaluate correlation between parameters in the experimental groups was used Spearman's partial rank-order correlation; the correlation is statistically significant if $p<0,05$. To evaluate the nature of relationship between parameters in the experimental groups and to compose an equation that describes this relationship the regression analysis with the selection of regressive model was made. The description of all quantitative characters was made with the median and 25 and 75 percentiles.

By the data analysis the arithmetical averages and the values of standard deviate were determined in connection with the descriptive statistics. To evaluate relationship between dynamic-static balance, legs and foots volume, body weight index and fat mass ratio of the female wrestlers the Spearman's correlative analysis was used as a non-parametric test. All the tests were made according to SPSS21.0 (SPSS Inc., Chicago, IL), and the level of significance was determined as 0,001 and 0,005 .

\section{Results discussion}

By the different literature sources, the determination of statokinesiogram area is performed as a confidence ellipse area counting (containing 90\%-95\% of discrete positions). That's why the area of statokinesiograms received from the stabiloplatform and from the tablet PC differs at about $10-15 \%$. The stabiloplatform counts the area of confidence ellipse, containing $95 \%$ of discrete positions, while the tablet PC counts the area of confidence ellipse, containing $90 \%$ of discrete positions.

Table 1. Stabilometric values of female children-wrestlers before load

\begin{tabular}{|l|c|c|}
\hline \multicolumn{1}{|c|}{ Parameter } & \multicolumn{2}{c|}{ Stabiloplatform } \\
\hline \multicolumn{1}{|c|}{ Eyes status } & Opened & Closed \\
\hline Median $[25 \% ; 75 \%]$ & $240[186,25 ; 271,5]$ & $377[312 ; 464,25]$ \\
\hline Changes percentage & \multicolumn{2}{|c|}{$153,5 \%$} \\
\hline Minimum value & 119 & 203 \\
\hline
\end{tabular}


Maximum value

663

1387

Table 2. Stabilometric values of female children-wrestlers after load

\begin{tabular}{|l|c|c|}
\hline \multicolumn{1}{|c|}{ Parameter } & \multicolumn{2}{c|}{ Stabiloplatform } \\
\hline \multicolumn{1}{|c|}{ Eyes status } & Opened & Closed \\
\hline Median $[25 \% ; 75 \%]$ & $240[200,25 ; 271,5]$ & $390[312 ; 464,25]$ \\
\hline Changes percentage & 111 & 198 \\
\hline Minimum value & 678 & 1393 \\
\hline Maximum value & & \\
\hline
\end{tabular}

Table 3. Stabilometric values of the control group

\begin{tabular}{|l|c|c|}
\hline \multicolumn{1}{|c|}{ Parameter } & \multicolumn{2}{c|}{ Stabiloplatform } \\
\hline \multicolumn{1}{|c|}{ Eyes status } & Opened & Closed \\
\hline Median $[25 \% ; 75 \%]$ & $143,5[75,3 ; 209,5]$ & $305,0[191,3 ; 436,5]$ \\
\hline Changes percentage & 39,0 & 51,0 \\
\hline Minimum value & 568,0 & 1605,0 \\
\hline Maximum value & \multicolumn{2}{|c|}{$212,5 \%$} \\
\hline
\end{tabular}

*Mann-Whitney U-test, the differences are statistically significant by the $\mathrm{p}$ value $<0,05$

There was determined statistically significant positive relationship of the investigated parameters changes between groups. We can make a conclusion that stabilometry can provide the reliable data concerning wrestler's lassitude level. Analogues data were received with the rating of perceived exertion by Borg's scale.

\section{Conclusions}

As the result we can conclude that the offered postural balance research method is valid for the wrestler's lassitude rating and can be used as a component of the complex athletes control system.

\section{References}

1. A.N. Korzhenevski, B.A. Podlivaev, N.V. Smirnova, B.I. Tarakanov, Scientific notes of Lesgaft University, 8(114), 89-93 (2014)

2. A.N. Korzhenevski, B.A. Podlivaev, N.V. Smirnova, B.I. Tarakanov, Scientific notes of Lesgaft University, 12(118), 110-117 (2014)

3. A.S. Kuznetsov, E.N. Usmanova, O.V. Kolomytseva, Russian Journal of Physical Education and Sport, 14(2), 89-96 (2014)

4. B. Podlivaev, Yu. Shakhmuradov, V. Vysotskaya, A. Gusova A, Women's freestyle wrestling (M., 2019)

5. M. Billot, Eur. J. Appl. Physiol, 109, 669-680 (2010)

6. Hammami R. et al. Hi. Hum. Kinet, 8, 33-41 (2014)

7. Hrysomallis C., Sports Med, 41(3), 221-232 (2011)

8. A.M. Andreeva, E.B. Akimov, K.A. Bochaver, Motor Control (2016) 
9. A.S. Nazarenko, F.A. Mazliev, N.Sh. Khasnutdinov. Materials of the All-Russian scientific-practical conference with international participation (Kazan, 2016)

10. A.S. Nazarenko, A.S. Chinkin, Science and Sport: Modern Trends, 7(2), 78-85 (2015)

11. A.S. Nazarenko, A.S. Chinkin, Science and Sport, Current Trends, 6(1), 19-23 (2015)

12. C.H. Lin, H.Y. Lee, J.J. Chen, J. Physiological Measurement, 27, 119-130 (2006)

13. L. Angyan, T. Teczely, Z. Anhyan, J.Acta Physiologica Hungarica, 94, 289-299 (2007)

14. A.A. Savin, A.A. Melnikov, Bulletin of Udmurt University, 6, 97-103 (2010)

15. F.B. Horak, J. Age and Ageing, 35(2), 7-11 (2006)

16. A.A. Melnikov, Physical education and sports training, 2(28) (2019)

17. V.S. Feshchenko, M.V. Panyukov, V.P. Plotnikov, Journal of the Russian Association for Sports Medicine and Rehabilitation of Patients and Disabled, 1(28), 25-27 (2009)

18. S.A. Likhachev, A.N. Kachinsky, Neurology and neurosurgery in Belarus, 2(6), 135-147 (2010)

19. N.V. Latyshev, V.V. Prikhodko, Physical education of students, April 12, 2012.

20. Nerys Williams, Occupational Medicine, 67(5), 404-405, URL: https://doi.org/10.1093/occmed/kqx063 